\title{
Percepções de agentes de combate a endemias e da população quanto aos fatores que influenciam na proliferação do mosquito Aedes aegypti, Chapecó (SC)
}

\author{
Fabíola Inês Salvi \\ Bióloga e Médica Veterinária (Unoesc), Mestre em Ciências da Saúde (Unochapecó) \\ $\square$ fabiola.salvi@unochapeco.edu.br
}

Nadine Martinelli Da Silveira

Graduada em Odontologia (Unochapecó)

$\bowtie$ nadinemartinelli@unochapeco.edu.br

\section{Maria Assunta Busato}

Graduada em Ciências e Biologia (Universidade de Passo Fundo), Doutora em Biologia (Universidade de Barcelona). Professora do Programa de Pós-Graduação em Ciências da Saúde da Universidade Comunitária da Região de Chapecó, Chapecó, SC, Brasil

$\triangle$ assunta@unochapeco.edu.br

\section{Walter Antônio Roman Júnior}

Graduado em Farmácia (UFSC), Mestre em Ciências Farmacêuticas (Universidade Estadual Paulista Júlio de Mesquita Filho - Unesp), Doutor Ciências Farmacêuticas (UFPR). Professor do Programa de Pós-Graduação em Ciências da Saúde da Universidade Comunitária da Região de Chapecó, Chapecó, SC, Brasil

\section{\romanwa@unochapeco.edu.br}

\section{Junir Antônio Lutinski}

Graduado em Ciências Biológicas (Unoesc), Mestre em Ciências Ambientais (Unochapecó), Doutor em Biodiversidade Animal (UFSM). Professor do Programa de Pós-Graduação em Ciências da Saúde da Universidade Comunitária da Região de Chapecó, Chapecó, SC, Brasil

$\bowtie$ junir@unochapeco.edu.br

\begin{abstract}
Resumo:
O mosquito Aedes aegypti caracteriza-se como uma espécie sinantrópica e antropofílica que apresenta preferência e facilidade em proliferar áreas urbanas. É considerado o principal vetor de viroses como a Febre Amarela, Dengue, Febre Chikungunya e Zika vírus. Há uma carência de estudos que abordem a percepção ambiental dos diferentes atores envolvidos no combate e controle desse mosquito em nível local. Este estudo objetivou descrever as percepções de Agentes de Combate a Endemias (ACE) e da população quanto aos fatores que influenciam na proliferação do A. aegypti. 0 estudo teve como referência geográfica o município de Chapecó localizado no estado de Santa Catarina. A coleta de dados contemplou ACE ativos no programa municipal de controle da dengue (PMCD) e a população. Foram excluídos cidadãos menores de 18 anos, acima de 75 anos e aqueles que residiam no local há menos de um ano. A coleta de dados foi realizada em outubro de 2017. Foram utilizados um questionário (ACE) e um roteiro de entrevistas (população). Os dados foram tabulados, caracterizados e avaliados quanto às frequências. Foram entrevistados $41 \mathrm{ACE}$ e 200 cidadãos. Ao todo, $61 \%$ dos ACE citaram a gestão inadequada de resíduos sólidos como facilitador para a proliferação do vetor. 0 acúmulo de resíduos em terrenos baldios foi citado por 71\% da população entrevistada. Este estudo demonstrou que os sujeitos da pesquisa têm o conhecimento necessário para atuar sobre a infestação do vetor. Porém, acredita-se que assimilação dessa informação e posterior transformação em atitudes proativas seja falha. Fato confirmado pela população que apontou haver circulação suficiente de informações e, por outro lado, pelos ACE indicando a falta de participação da comunidade em geral nas ações de combate e controle.

Palavras-chave: Ambiente e saúde, Educação em saúde, Promoção da saúde, Vigilância ambiental em saúde.
\end{abstract}




\title{
Agents to Combat Endemics and the population perceptions of regarding the factors that influence the proliferation of the Aedes aegypti mosquito, Chapecó (SC)
}

\begin{abstract}
:
The Aedes aegypti mosquito is characterized as a synanthropic and anthropophilic species that shows preference and ease in proliferating urban areas. It is considered the main vector of viruses such as Yellow Fever, Dengue, Chikungunya Fever and Zika virus. There is a lack of studies that address the environmental perception of the different actors involved in controlling this mosquito at the local level. This study aimed to describe the perceptions of Agentes de Combate à Endemias (ACE) and the population regarding the factors that influence the proliferation of A. aegypti. The study had as geographical reference the city of Chapecó (SC). Data collection included ACE active in the municipal dengue control program (PMCD) and the population. Citizens under 18 years old, over 75 years old and those who lived in the place for less than a year were excluded. Data collection was carried out in October 2017. A questionnaire (ACE) and an interview script (population) were used. The data were tabulated, characterized and evaluated for frequencies. A total of $41 \mathrm{ACE}$ and 200 citizens were interviewed. In all, $61 \%$ of ACE cited the inadequate management of solid waste as a facilitator for the proliferation of the vector. The accumulation of waste in vacant lots was mentioned by $71 \%$ of the interviewed population. This study demonstrated that the research subjects have the necessary knowledge to act on the vector infestation. However, it is believed that assimilation of this information and subsequent transformation into proactive attitudes is flawed. This fact was confirmed by the population, who pointed out that there was sufficient circulation of information and, on the other hand, by the ACE indicating the lack of participation by the community in general in the actions of combat and control.
\end{abstract}

Keywords: Environment and health, Health education, Health promotion, Environmental health surveillance.

\section{Percepciones de los Agentes de Combate a Endemias y la población con respecto a los factores que influyen en la proliferación del mosquito Aedes aegypti, Chapecó (SC)}

\begin{abstract}
Resumen:
El mosquito Aedes aegypti se caracteriza por ser una especie sinantrópica y antropofílica con preferencia y facilidad en zonas urbanas en proliferación. Se considera el vector principal de virus como la fiebre amarilla, el dengue, la fiebre chikungunya y el virus del Zika. Faltan estudios que aborden la percepción ambiental de los diferentes actores involucrados en la lucha y el control de este mosquito a nivel local. Este estudio tuvo como objetivo describir las percepciones de los Agentes de Combate à Endemias (ACE) y la población con respecto a los factores que influyen en la proliferación de A. aegypti. El estudio tuvo como referencia geográfica la ciudad de Chapecó (SC). La recopilación de datos incluyó a ACE activa en el programa municipal de control del dengue (PMCD) y la población. Los ciudadanos menores de 18 años, mayores de 75 años y aquellos que vivieron en el lugar durante menos de un año fueron excluidos. La recolección de datos se realizó en octubre de 2017. Se utilizó un cuestionario (ACE) y un guión de entrevista (población). Los datos fueron tabulados, caracterizados y evaluados para frecuencias. Se entrevistaron 41 ACE y 200 ciudadanos. En total, el 61\% de ACE citó el manejo inadecuado de los residuos sólidos como un facilitador para la proliferación del vector. El 71\% de la población entrevistada mencionó la acumulación de residuos en lotes vacantes. Este estudio demostró que los sujetos de investigación tienen el conocimiento necesario para actuar sobre la infestación de vectores. Sin embargo, se cree que la asimilación de esta información y la posterior transformación en actitudes proactivas es errónea. Este hecho fue confirmado por la población, quien señaló que había suficiente circulación de información y, por otro lado, por los ACE indicando la falta de participación de la comunidad en general en las acciones de combate y control.
\end{abstract}

Palabras clave: Medio ambiente y salud, Educación sanitaria, Promoción de la salud, Vigilancia de la salud ambiental. 


\section{INTRODUÇÃO}

A promoção da saúde (PS) repercute sobre o processo saúde-doença e seus determinantes, representa o resultado de uma ponte entre os saberes técnicos e populares e a mobilização de recursos institucionais e comunitários, públicos e privados, para o enfrentamento de seus desafios (BUSS, 2000; CZERESNIA; FREITAS, 2003). Norteada por um conjunto de princípios como qualidade de vida, saúde, solidariedade, equidade, democracia, cidadania, desenvolvimento, participação e parceria, a PS também é uma combinação de estratégias intersetoriais como as ações do estado, da comunidade, do indivíduo e do sistema de saúde (CAMPOS; NETO, 2008). Estas estratégias capacitam a comunidade para atuar na melhoria da sua qualidade de vida e também a ter controle sobre o processo como um todo (BUSS, 2000; CZERESNIA; FREITAS, 2003; ANS, 2009; DALMOLIN et al., 2011). Por outro lado, a prevenção de agravos tem por finalidade evitar a doença. Baseada na Epidemiologia, a prevenção busca o controle da transmissão de doenças infecciosas e a redução do risco de doenças degenerativas ou outros agravos específicos (CZERESNIA; FREITAS, 2003; ANS, 2009).

O mosquito Aedes aegypti (Linneaus, 1762) (Diptera: Culicidae) é uma espécie sinantrópica e antropofílica que tem preferência e facilidade em proliferar áreas urbanas densamente povoadas (OLIVEIRA, 2015; ZARA et al., 2016). É uma espécie de origem africana que acompanhou o ser humano através de migrações e possivelmente foi introduzido nas Américas através de navios negreiros (BRAGA; VALLE, 2007a, 2007b). Quando adulto possui porte de aproximadamente $5 \mathrm{~mm}$ de comprimento, tendo o corpo escuro e as pernas marcadas por faixas brancas, conferindo-lhe aspecto "tigrado". Possui um desenho na forma de lira no tórax o que diferencia o diferencia da espécie Aedes albopictus (Skuse, 1894) (MARCONDES, 2011; OLIVEIRA, 2015). Atualmente, a distribuição geográfica do A. aegypti inclui a maior parte das áreas tropicais e subtropicais, estando presente na África, Ásia, Américas e Oceania (BRAGA; VALLE, 2007a; OLIVEIRA, 2015). Pode transportar consigo um grupo de vírus conhecidos como arbovírus, que têm parte de seu ciclo replicativo desenvolvido nesses mosquitos, como em outros artrópodes reservatórios e transmissores (LOPES; NOSAWA; LINHARES, 2014). Estima-se que haja mais de 545 espécies de arbovírus, dentre as quais mais de 150 capazes de causar doenças aos seres humanos (LOPES; NOSAWA; LINHARES, 2014). Atualmente, é considerado o principal vetor de viroses como a Febre 
Amarela, Dengue, Febre Chikungunya e Zika Vírus (MARCONDES, 2011; OLIVEIRA, 2015; REY; LOUBINOS, 2015; ZARA et al., 2016).

A adaptação ao meio urbano permite que os criadouros de A. aegypti ocorram nos entornos de edificações ficando perto do ser humano, facilitando sua alimentação (MARCONDES, 2011; OLIVEIRA, 2015). A fêmea do dessa espécie consegue fazer várias ingestões de sangue durante um mesmo ciclo gonadotrófico e costuma depositar seus ovos em mais de um criadouro, elevando sua eficiência reprodutiva (REY; LOUBINOS, 2015; ZARA et al., 2016).

Existem inúmeros estudos acerca da biologia e padrões de infestação do A. aegypti (CESAR; LABINAS, 2007; BESSERA et al., 2010; OLIVEIRA, 2015) embora poucos abordam as características regionais e locais e suas interações com a população humana, aspectos culturais e sociais intrínsecos de localidade. Além de fatores climáticos como a temperatura e a pluviosidade, fatores antrópicos também interferem na dinâmica populacional desse vetor, tais como: serviços como a coleta e a destinação de resíduos sólidos urbanos, a disponibilidade de água potável e as ações humanas decorrentes do processo de urbanização. Nesse sentido, faz-se necessário o conhecimento desses fatores para nortear a adoção de medidas de controle nas esferas regionais e locais (COSTA et al., 2008).

Tauil (2001) enfatiza a importância dos fatores sociais na transmissão da Dengue, destacando o crescimento populacional, o acelerado processo de urbanização e as fragilidades dos sistemas de saúde, que juntos configuram-se fatores fundamentais para a inserção de epidemias de Dengue. É fato que em todo planeta as pessoas mais vulneráveis ao adoecimento são aquelas menos favorecidas social e economicamente, por não terem acesso a recursos sanitários, emprego, moradia segura, entre outros fatores que conferem a qualidade de vida. Os problemas de saúde estão associados às condições de vida e trabalho no qual as pessoas estão inseridas (AKERMAN et al., 2011).

Os assentamentos urbanos representam a principal modificação na vida social humana e também a principal ação antrópica sobre o ambiente. Existe uma estreita associação entre cidades e o desenvolvimento humano devido às oportunidades oferecidas por uma metrópole (JARA; HIDALGO; HANSEN, 2011). Ser habitante de uma cidade, em tese, traz vantagens para a saúde, pois há água potável, energia elétrica, habitação, oportunidade de emprego e educação, além de facilidade no acesso a programas e serviços de saúde. Porém, 
pela falta de planejamento, aumento da densidade populacional, as alterações do ambiente podem gerar insalubridades como a poluição ambiental resultando em risco de danos à saúde (JARA; HIDALGO; HANSEN, 2011; SEGURADO; CASSENOTE; LUNA, 2016).

Tauil (2001) demonstra que a partir da década de 1960 houve um intenso movimento migratório nos países subdesenvolvidos, culminando no "inchaço" das metrópoles que não conseguiram absorver essa onda migratória. A dimensão da migração não foi prevista, com isso, não houve planejamento de expansão das estruturas de moradia e saneamento básico para acomodar os imigrantes. $O$ autor também ressalta que o sistema produtivo moderno atua de forma perversa neste caso, pois gera grandes quantidades de resíduos descartáveis. Com um serviço de coleta de resíduos ineficiente, esses materiais em muitos casos acabam em terrenos baldios e/ou lixões, desprotegidos das chuvas, gerando criadouros para o A. aegypti.

Neste sentido, este estudo objetivou descrever as percepções de Agentes de Combate a Endemias (ACE) e da população quanto aos fatores que influenciam na proliferação do A. aegypti no município de Chapecó, Santa Catarina.

\section{MATERIAL E MÉTODOS}

\section{Caracterização da pesquisa}

O estudo teve um caráter transversal e uma abordagem quantitativa. Rouquayrol e Almeida Filho (1999) definem a pesquisa transversal como o estudo no qual o fator e o efeito são observados em um mesmo momento histórico. Estudos transversais apresentam-se como um recorte de uma população, realizado por meio de uma amostragem, analisando-se nos integrantes da amostra, a presença ou ausência da exposição e a presença ou ausência do efeito. São empregados quando se deseja estimar a frequência com que um determinado evento se manifesta em uma população específica, além dos fatores associados com o mesmo (BASTOS; DUQUIA, 2007). Neste sentido, a investigação foi conduzida a partir de um levantamento de dados, obtidos a partir de questionários aplicados aos Agentes de Combate a Endemias (ACE) e à população. 


\section{Local de estudo}

O estudo teve como referência geográfica a cidade de Chapecó (SC). Localizado na região oeste de Santa Catarina (Latitude: $27^{\circ} 05^{\prime}$ 47" S; Longitude: $52^{\circ} 37^{\prime} 06^{\prime \prime} \mathrm{W}$ ), altitude de 674 metros. 0 município possui área territorial de $626,06 \mathrm{~km}^{2}$, população estimada em 220.367 habitantes e área urbana aproximada de $36 \mathrm{~km}^{2}$ (IBGE, 2019). Possui clima mesotérmico, temperatura média variando entre $15 \mathrm{a} 25{ }^{\circ} \mathrm{C}$, umidade relativa do ar média aproximada de 73\% (INPE, 2016).

Chapecó é considerada capital nacional das agroindústrias, por sediar algumas das maiores unidades industriais processadoras e exportadoras de derivados de suínos e aves. Possui PIB per capita de $\mathrm{R} \$ 37.303,11$, e Índice de Desenvolvimento Humano Municipal (IDHM) de 0,790 (IBGE, 2019). 0 município também é um ponto estratégico para negócios no Sul do Brasil, sendo referência regional em prestação de serviços e formação profissional na área da saúde (SEBRAE, 2013).

O município de Chapecó vem monitorando a infestação do mosquito A. aegypti desde 1999, quando a espécie foi registrada pela primeira vez na cidade. $O$ índice de Infestação Predial (IIP) tem apresentado uma crescente desde o anos de 2010, alcançando a casa de $6 \%$ dos imóveis no ano de 2015 e 2016, se mantendo neste nível desde então.

\section{Sujeitos participantes da pesquisa}

A coleta de dados contemplou dois grupos populacionais:

a) Agentes de Combate a Endemias: foram incluídos os ACE alocados no setor de Vigilância em Saúde Ambiental da Secretaria de Saúde, ativos no programa municipal de controle da dengue (PMCD) há pelo menos um ano e que aceitaram participar do estudo, mediante assinatura de Termo de Consentimento Livre e Esclarecido.

b) População: foram visitadas 200 imóveis nos 10 bairros que apresentaram os maiores índices de infestação predial (IIP) no ano de 2016. Em cada bairro, foram visitados aleatoriamente 20 imóveis. Responderam o questionário cidadãos maiores de 18 anos, residentes no imóvel visitado e que concordaram em participar da pesquisa mediante assinatura do Termo de consentimento livre e esclarecido. Foram excluídos cidadãos 
menores de 18 anos, acima de 75 anos e aqueles que residiam no local há menos de um ano. Considerou-se população de Chapecó qualquer cidadão residente no município, entendendo-se que todo residente é atendido pelo PMCD, neste caso.

\section{Coleta de dados}

Agentes de Combate a Endemias: Para a coleta de dados foi escolhido como instrumento de pesquisa à aplicação de um questionário semiestruturado. As questões foram construídas a partir da literatura sobre o tema em estudo. A coleta de dados foi realizada em outubro de 2017, durante reunião de rotina dos ACE nas dependências da Secretaria de Saúde de Chapecó. População: o instrumento adotado foi uma entrevista semiestruturada. As entrevistas foram realizadas no período de novembro e dezembro de 2017 nos próprios domicílios dos participantes.

\section{Análise de dados}

Os dados foram tabulados em um banco de dados com auxílio do pacote Office 2008 (MICROSOFT Inc., 2016). Posteriormente, as respostas foram categorizadas e avaliadas quanto às frequências para demonstrar padrões de ocorrência na amostra.

\section{Aspectos éticos}

Este estudo atendeu as determinações da Resolução 466/2012 da Comissão Nacional de Ética e Pesquisa com Seres Humanos (Conselho Nacional de Saúde, 1996) e foi previamente aprovado pelo Comitê de Ética em Pesquisa com Seres Humanos (CEP) na Universidade Comunitária Regional de Chapecó, sob parecer número 232308 e CAAE número 75.933317.1.0000.0116. 


\section{RESULTADOS}

Foram entrevistados 41 (quarenta e um) Agentes de Combate a Endemias (n=41) e 200 (duzentos) cidadãos / população $(\mathrm{n}=200)$ em 10 (dez) bairros de Chapecó. Quanto a caracterização sociodemográfica, a média de idade dos ACE foi de 39,7 anos, sendo 90,2\% (n= 37) do sexo feminino e 9,8\% (n=4) masculino. Para a população, a média de idade foi de 37,7 anos, com 59,5\% ( $n=119)$ pertencentes ao sexo feminino e 40,5\% ( $n=81)$ masculino. Dentre os ACE, 58,6\% ( $n=58,6)$ declararam ter ensino médio completo; $17 \%(n=7)$, ensino superior incompleto; 9,8\% $(n=4)$ ensino fundamental incompleto; 9,8\% $(n=4)$ ensino fundamental completo; e 4,9\% ( $n=2)$ ensino superior completo.

A população apresentou idade média de 37,7 anos, sendo 32,5\% ( $n=65)$ declaram ter ensino médio completo, 26,5\% ( $n=53)$ ensino fundamental completo, 13,5\% ( $n=27)$ ensino superior completo, 11\% $(n=22)$ ensino superior incompleto, 7,5\% $(n=15)$ ensino médio incompleto, $6 \%(n=12)$ pós-graduação ou acima e $1 \%(n=2)$ optou por não responder a pergunta (Tabela 1).

Tabela 1 - Perfil sociodemográfico de Agentes de Combate a Endemias e da População participantes da pesquisa, município de Chapecó. Agentes de Combate a Endemias (ACE), desvio padrão (DP), número de participantes (n) e percentual (\%).

\begin{tabular}{lllll}
\hline \multicolumn{1}{c}{ CATEGORIAS } & & ACE & & POPULAÇÃO \\
\hline Idade & Média & DP & Média & DP \\
Sexo & 39,70 & 10,5 & 37,70 & $\mathbf{\%}$ \\
Masculino & $\mathbf{N}$ & $\mathbf{\%}$ & $\mathbf{n}$ & 40,5 \\
Feminino & 4 & 9,8 & 81 & 59,5 \\
Escolaridade & 37 & 90,2 & 119 & $\mathbf{\%}$ \\
& $\mathbf{N}$ & $\mathbf{\%}$ & $\mathbf{n}$ & 2,0 \\
Ensino fundamental incompleto & & & 46,5 \\
Ensino fundamental completo & & & 53 & 7,5 \\
Ensino médio incompleto & 4 & 9,8 & 15 & 32,5 \\
Ensino médio completo & 4 & 9,8 & 65 & 11,0 \\
Ensino superior incompleto & 24 & 58,6 & 22 & 13,5 \\
Ensino superior completo & 7 & 17,0 & 27 & 6,0 \\
Pós-Graduação ou acima & 2 & 4,9 & 12 & 1,0 \\
Não responderam & & & 2 & \\
\hline
\end{tabular}

Fonte: Os autores (2019) 
Ao todo, 82,9\% (n=34) dos ACE responderam que algumas regiões da cidade são mais propensas a proliferação do vetor A. aegypti. Quando solicitado exemplos, $24,4 \%$ ( $n=10)$ responderam que regiões que abrigam usinas de reciclagem são propícias à proliferação do vetor, 22\% (n=9) citaram regiões de periferia/carentes, 19,5\% $(n=8)$ regiões com carência no saneamento, $12,2 \%(n=5)$ regiões centrais, $7,3 \%(n=3)$ regiões com intermitência no abastecimento de água e 4,9\% (n=2) citaram regiões com maior número de terrenos baldios (Tabela 2).

Tabela 2 - Percepções de Agentes de Combate a Endemias acerca da influência do território sobre a flutuação da população do vetor, município de Chapecó. Agentes de Combate a Endemias (ACE) e número de participantes (n) e percentual (\%).

\begin{tabular}{lll}
\hline \multicolumn{1}{c}{ TERRITÓRIO NAS PERCEPÇÕES DOS ACE } & n & \% \\
\hline Sim & 34 & 82,9 \\
Não & 6 & 14,6 \\
Não sei & 1 & 2,8 \\
\hline Regiões carentes de saneamento & 8 & 19,5 \\
Regiões que hospedam usinas de reciclagem & 10 & 24,4 \\
Regiões centrais & 5 & 12,2 \\
Regiões de periferia/carentes & 9 & 22,0 \\
Regiões com maior número de terrenos baldios & 2 & 4,9 \\
Regiões com intermitência no abastecimento de água & 3 & 7,3 \\
\hline
\end{tabular}

Fonte: Os autores (2019).

Acerca da influência dos serviços de saneamento básico, 61\% (n=25) dos ACE citaram a gestão inadequada de resíduos sólidos (deposição dos resíduos em locais impróprios como terrenos baldios e vias públicas) como facilitador para a proliferação do vetor e $14,6 \%$ (n=6) citaram a intermitência no abastecimento de água potável. o acúmulo de resíduos em terrenos baldios foi citado por 71\% $(n=142)$ da população entrevistada, 69,5\% ( $n=139)$ citaram acúmulo de resíduos nos domicílios e 47\% (n=95) apontaram a gestão inadequada dos resíduos sólidos.

Ao serem questionados acerca da condição socioeconômica da população e sua influência sobre a proliferação do vetor, $68,3 \%(n=28)$ dos ACE entrevistados responderam que 
há influência e 37,7\% (n=13) que não há influência. Quanto ao tipo de edificações e atividades econômicas com maior probabilidade de abrigar focos do vetor, 41,5\% ( $\mathrm{n}=17)$ dos ACE citaram como condição favorável os ferros-velhos, 41,5\% ( $\mathrm{n}=17)$ usinas de reciclagem, 36,6\% ( $\mathrm{n}=15)$ borracharias, 17,7\% ( $n=7)$ floriculturas, 14,6\% $(n=6)$ cemitérios, 9,8\% $(n=4)$ construção civil, 4,9\% ( $n=2)$ escolas e 4,9\% ( $n=2)$ indústrias. Para 70,5\% ( $n=141)$ da população os ferros-velhos, 51\% ( $\mathrm{n}=102)$ usinas de reciclagem, 35\% ( $\mathrm{n}=70)$ floriculturas, 16\% $(\mathrm{n}=32)$ cemitérios, 7,5\% ( $\mathrm{n}=15)$ terrenos baldios e $3 \%(n=6)$ construção civil contribuem para a proliferação do mosquito $A$. aegypti.

De acordo com a classificação do Programa Municipal de Controle da Dengue (PMCD), para os depósitos com maiores potencialidades de se converter em criadouros, 100\% ( $n=41)$ dos ACE citaram o tipo D2 (passíveis de remoção: materiais descartáveis, garrafas, latas e similares), 65,9\% ( $\mathrm{n}=27)$ o tipo D1 (pneus e materiais rodantes), 56,1\% ( $\mathrm{n}=23)$ o tipo A2 (criadouros ao nível de solo: cisternas, tonéis e similares), 48,8\% ( $\mathrm{n}=20)$ o tipo C (fixo: piscinas, tanques em obras, calhas, ralos), 7,3\% ( $n=3)$ depósitos tipo B (móveis: pratos de flores, bebedouros de animais, recipientes de degelo de geladeira e similares) e 7,3\% ( $n=3)$ depósitos tipo E (naturais: folhagens, bromélias e similares).

Sobre a influência dos fatores climáticos sobre a população do mosquito A. aegypti, 92,9\% ( $n=39)$ dos ACE concordam que há influência do clima. Quando questionados sobre a forma como o clima influencia, $56,2 \%$ ( $n=23$ ) citaram que temperaturas elevadas e a umidade favorecem, $14,7 \%(n=11)$ citaram que a umidade favorece e 9,8\% ( $n=4)$ citaram que as temperaturas altas favorecem a proliferação do vetor. Dentre a população, 95,5\% ( $\mathrm{n}=192)$ responderam que há influência do clima. Sobre a forma como o clima influencia, 13,5\% ( $\mathrm{n}=27)$ citaram que temperaturas altas, $6 \%(n=12)$ citaram que temperaturas altas e umidade e 5,5\% (n=11) citaram que a umidade favorece a proliferação do vetor (Gráfico 1).

Quanto à sazonalidade, $72,5 \%(\mathrm{n}=145)$ da população citou o verão como o período mais propício para a proliferação, $54,5 \%(n=109)$ a primavera $4 \%(n=8)$ outono e 3,5\% inverno $(n=7)$. Ao todo, 39\% ( $\mathrm{n}=16)$ dos ACE consideram como regular a participação da comunidade, 34,2\% ( $n=14$ ) insuficiente e $26,8 \%$ ( $n=11$ ) consideraram boa (Gráfico 2). 
Gráfico 1 - Percepções de Agentes de Combate à Endemias e da População sobre influência dos fatores climáticos sobre a proliferação do mosquito Aedes aegypti, município de Chapecó.

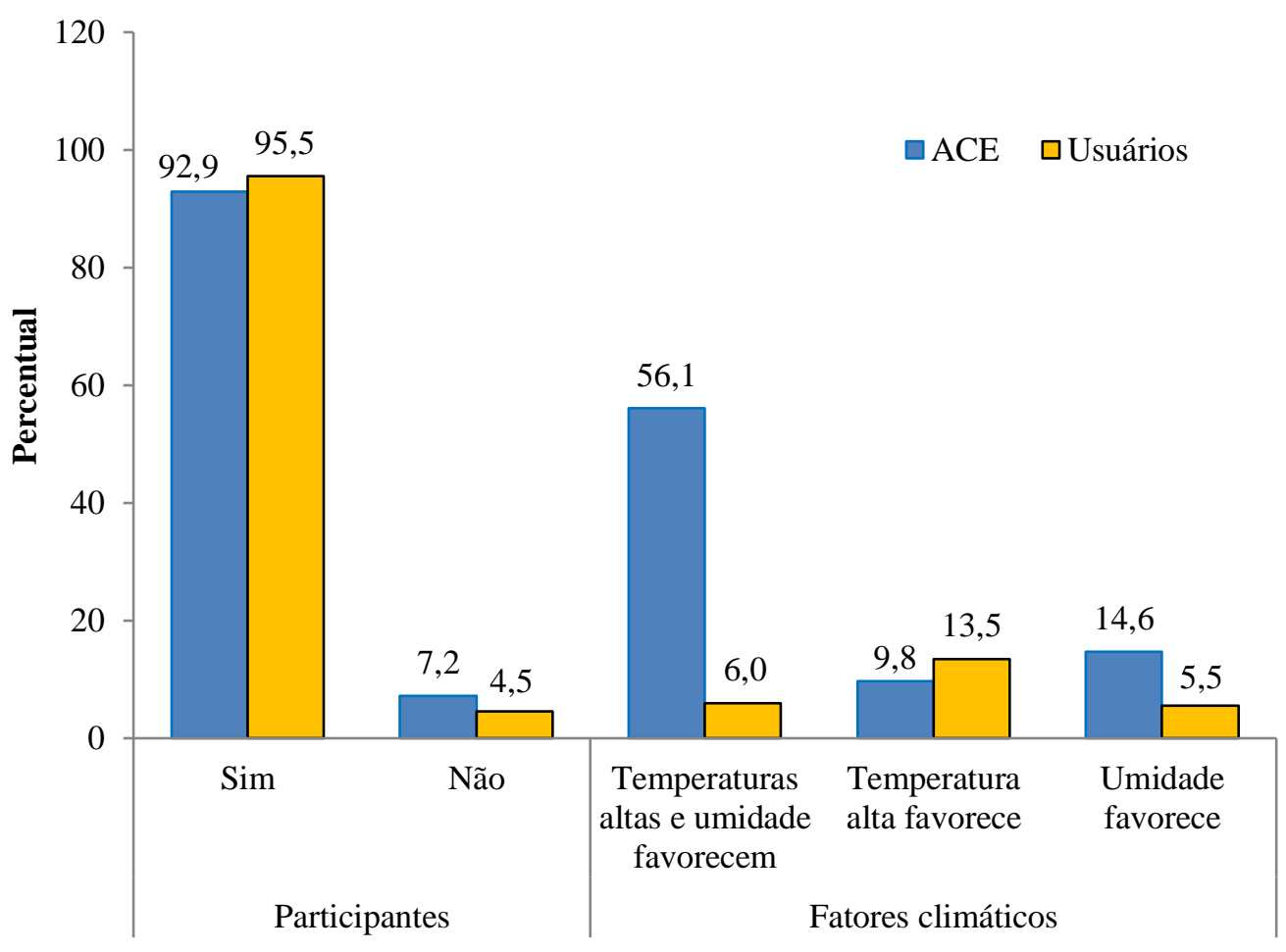

Fonte: Os autores (2019)

Gráfico 2 - Percepções de Agentes de Combate à Endemias sobre a participação da comunidade nas ações de controle da proliferação do mosquito Aedes aegypti, município de Chapecó. As barras verticais representam o erro padrão.

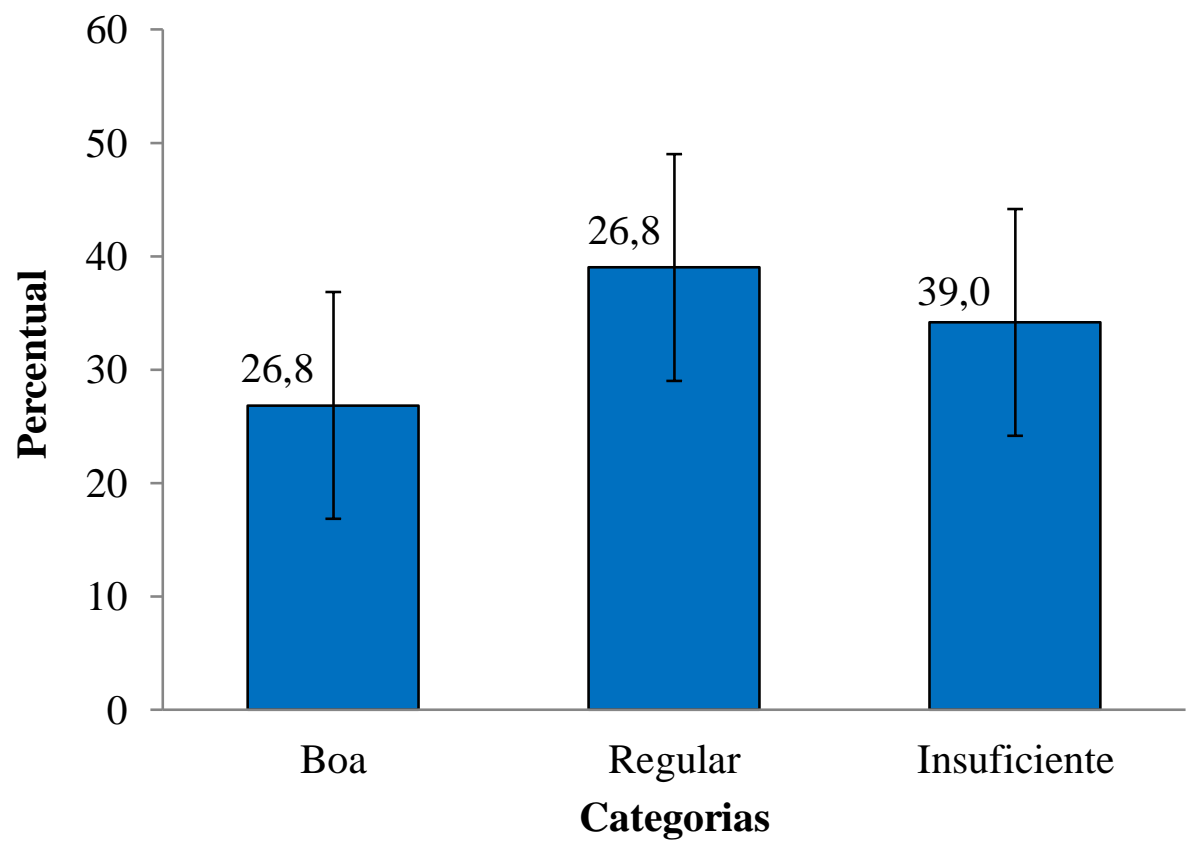

Fonte: Os autores (2019). 
A população foi questionada sobre a disponibilidade de informações sobre o vetor e ações de prevenção e controle desenvolvidos pelo PMCD. Destes, $84 \%(n=168)$ responderam há disponibilidade de informações suficientes para o controle da população de A. aegypti, $9 \%$ (n=18) não sabem e 7\% (n=14) responderam que não há informações suficientes sobre o vetor. Ainda, segundo a percepção da população, para 94\% ( $\mathrm{n}=188)$ dos entrevistados é necessária maior participação da comunidade e para $47 \%(\mathrm{n}=94)$ é necessária maior fiscalização pelos órgãos competentes.

\section{DISCUSSÃo}

O perfil sociodemográfico dos entrevistados é semelhante para os dois grupos de sujeitos. Dentre os ACE, a maioria é do sexo feminino, com média de idade de 39,7 anos e ensino médio completo. O maior número de ACE do sexo feminino, segundo Ferreira e Chiaravalloti Neto (2007), pode ser favorável. Numa pesquisa sobre as dificuldades da ação dos ACE no PMCD de São José do Rio Preto (SP), os autores perceberam que a população local tem maior afinidade com ACE do sexo feminino, por questões de segurança, melhor desempenho no trabalho e ainda sua afinidade pelos cuidados com a residência. Quanto à escolaridade, o predomínio do ensino médio completo está além do esperado, em virtude dos pré-requisitos para o cargo, fixados em edital de contratação, exigir apenas o Ensino Fundamental. Dentre a população, também há o predomínio do sexo feminino, porém com discreta diferença. A idade média foi de 37,7 anos e o ensino médio completo também foi a escolaridade predominante. Esses resultados corroboram com os valores encontrados pelo último CENSO (IBGE, 2013).

A infestação pelo A. aegypti está intimamente ligada com a produção desigual dos espaços urbanos. A precária infraestrutura das cidades, o deficitário sistema de abastecimento de água e destinação de resíduos propiciam a formação de novos criadouros do mosquito, aumentando sua população e, consequentemente, a predisposição para circulação de diferentes sorotipos da Dengue e demais doenças transmitidas pelo vetor (TAUIL, 2001; FEITOSA et al., 2016). 
A consciência do território e de suas dinâmicas, hábitos, modo de vida e práticas do cotidiano das pessoas, comunidades e instituições nele inseridas é uma ferramenta valiosa para o combate ao vetor, auxiliando na compreensão do porquê determinados locais sob condições ambientais e de saneamento semelhantes, ocorrem diferentes graus de infestação pelo A. aegypti (FEITOSA et al., 2016). Os ACE, em sua maioria, percebem o território em que estão inseridos como profissionais. Quando questionados sobre a influência do território e suas particularidades, $82,9 \%$ responderam que há influência citando como exemplo zonas que abrigam usinas de reciclagem, regiões carentes e com precariedade de saneamento como as mais propícias a instalação de criadouros do vetor. Esse fato é esperado e explicado dada a proximidade dos ACE com a comunidade local durante a realização de suas atividades.

A percepção e o entendimento da conexão entre estruturas e serviços de saneamento e as populações do vetor A. aegypti é significativa no processo de combate e prevenção não somente do vetor, mas das patologias por ele transmitidas. Nessa temática, os ACE citaram a gestão de resíduos sólidos como principal contribuinte para infestações, percepção também partilhada pela população que citou em sua maioria o acúmulo de resíduos em residências e terrenos baldios como determinantes. As afirmações dos sujeitos da pesquisa são validadas pela literatura em que vários artigos comprovam que o inadequado saneamento básico contribui como um dos fatores condicionantes para infestação (TAUIL, 2001; MENDONÇA; SOUZA; DUTRA, 2009; HORTA et al., 2013; FEITOSA; SOBRAL; JESUS, 2015; FEITOSA et al., 2016; ALMEIDA; SILVA, 2018). No município de Chapecó há serviço regular de coleta dos resíduos, contudo, hábitos da população como acumular materiais em quintais de suas residências ou descartá-los em terrenos baldios se configuram em um desafio relevante no controle de vetores.

Acerca da condição socioeconômica, 68,3\% dos ACE entrevistados associaram positivamente regiões carentes do município e a tendência a instalação de focos. Essa associação é controversa na comunidade científica. O movimento da saúde global (One Health) classifica a Dengue como doença negligenciada a perpetuadora da pobreza por apresentar incidência elevada em regiões carentes que possuem alta densidade populacional e precariedade ou ausência de saneamento básico (PIMENTA, 2015). No Brasil, as regiões mais afetadas pela doença e com maiores infestações são aquelas com renda per capita menor (FERREIRA; CHIARAVALLOTI NETO, 2007). 
Cabral e Freitas (2012), em estudo sobre casos de dengue nos municípios brasileiros no ano de 2010, propuseram associação entre a distribuição espacial, determinantes socioeconômicos e demográficos e casos de dengue com intuído de verificar a influência destes sobre sua epidemiologia. O estudo demonstrou que não houve associação entre os fatores socioeconômicos e a doença, e sim entre os fatores demográficos e a dengue, em que regiões com maior densidade populacional apresentaram mais casos da doença.

A percepção tanto de ACE, quanto da população sobre a associação de imóveis e atividades econômicas com características favoráveis para instalação do vetor revelou os ferros-velhos, usinas de reciclagem, floriculturas e borracharias como os mais propícios. Estas atividades econômicas apresentam tal risco porque fazem parte de uma rede de estabelecimentos que oferecem um grande número de potenciais criadouros. Ferros-velhos, usinas de reciclagem e borracharias trabalham com materiais descartados, na maioria dos casos, acondicionados sem proteção contra intempéries, oferecendo condições propícias para instalação do vetor (MACHADO; OLIVEIRA; SOUZA-SANTOS, 2009).

Em relação aos tipos de depósitos utilizados com maior frequência pelo vetor, $100 \%$ dos ACE citaram o tipo D2, seguido pelos tipos D1, A2 e C. Os depósitos do tipo D2 são compostos basicamente de materiais descartáveis, ou seja, resíduos e entulhos. Assim, é correto afirmar que, segundo a percepção dos ACE, a produção de criadouros artificiais oriundas da fragilidade no gerenciamento de resíduos é um dos fatores facilitadores para a instalação de novos criadouros do vetor no município de Chapecó. A frequência com que o depósito D2 e D1 foram citados corrobora com os números encontrados por Silva (2017) para o estado de Santa Catarina que encontrou padrão similar. Rossi e Silva (2008) também apontaram os depósitos do tipo D1 como os mais frequentes no estado de Santa Catarina nos períodos de 1998 a 2007.

A percepção ambiental se refere ao conhecimento do indivíduo sobre o meio ambiente, ou seja, tomar consciência sobre o meio no qual o mesmo está inserido. No caso da percepção do ambiente em relação à saúde coletiva, o indivíduo percebe a influência do meio sobre as mais diversas doenças e suas causas, formas de transmissão, prevenção e controle. Essa percepção leva o indivíduo a adotar atitudes com intuito de se proteger de doenças, influenciando diretamente sua ação individual na saúde da coletividade (SILVA; SILVA, 2012). 
A percepção da influência dos fatores climáticos na flutuação das populações do vetor se mostrou positiva. Mais de $90 \%$ dos entrevistados, nos dois grupos de sujeitos, apontaram a relação entre o clima e a proliferação do vetor. Em relação ao mecanismo de influência, os ACE demonstraram ter maior percepção do clima em sua totalidade, citando a associação entre pluviosidade e altas temperaturas. Já a população, em sua maioria, citou ou temperaturas altas ou pluviosidade, sem associar os dois fatores. A associação dos dois fatores climáticos demonstrada pelos ACE é esperada e benéfica para a prevenção. Dentre as atribuições do ACE, a orientação acerca da prevenção e controle do vetor é uma das mais relevantes e complexas. É necessário que o ACE tenha conhecimento da biologia e hábitos do vetor para que possa orientar de forma clara e segura a população sobre as formas de controle.

Seguindo a temática dos fatores climáticos, a população demonstrou ter conhecimento da interação entre sazonalidade e a flutuação da população do vetor, citando as estações verão e primavera como as mais propícias para o desenvolvimento. $\mathrm{O}$ fato de que as estações do ano com maiores temperaturas máximas e mínimas, ou seja, mais quentes, serem propícias à proliferação de insetos, neste caso mosquitos, é fruto de inúmeros estudos realizados pela comunidade científica somado ao conhecimento adquirido pela comunidade em geral a partir de experiências, vivências e observações do mundo.

A participação da comunidade no combate ao vetor é mais um dos elos da corrente na prevenção às arboviroses. Cabe à comunidade participar do PMCD e agir quando solicitada. Nesse sentido, os ACE classificaram o nível de participação da comunidade chapecoense no PMCD como insuficiente, citando a falta de sensibilização para a problemática. Silva e Silva (2012), num estudo sobre a percepção ambiental de moradores de um bairro de Boa Vista (RR) e a sua relação com a dengue, concluíram que os moradores não se veem como agentes sociais, não tendo noção de coletividade e não se responsabilizando pelos espaços públicos. Há consciência em relação ao cuidado de seu espaço, sua residência, mas este não se estende a comunidade em que o indivíduo se insere.

No estudo Silva et al. (2015) na cidade de Aracaju (SE), os sujeitos apontaram que a responsabilidade pelas atitudes de prevenção e controle da Dengue é da população, sendo ela responsável por evitar acúmulo de água, através da higiene e destinação correta de resíduos intra e peridomicilar. Tauil (2001) demonstrou a necessidade de adoção de hábitos ao 
cotidiano dos indivíduos para evitar potenciais criadouros e também destaca que a estratégia para a mudança do comportamento dos indivíduos seria a intensa mobilização comunitária e um processo continuado e sustentado de educação em saúde. Silva e Silva (2012) notaram que a maioria dos entrevistados tendem a esperar por medidas assistencialistas, transferindo a responsabilidade ao poder público, que deve disponibilizar agentes da saúde, fiscalizar, gerenciar resíduos acondicionados em vias públicas e terrenos baldios, por exemplo.

Sobre as demandas do PMCD, os dois grupos de sujeitos da pesquisa apontaram a participação social e o aumento da fiscalização como medidas a serem trabalhadas. A fiscalização e aplicação de sansões administrativas efetivamente são processos que obtém certo sucesso, porém a mudança de atitude da comunidade, diante do receio à punição recebida pelo descumprimento da "lei", afeta o processo empoderamento popular. Nesse sentido, o indivíduo será coagido à mudança de comportamento, não entendendo sua razão e tampouco sua conexão com sua própria saúde e seu ambiente, não lhe dando subsídios para agir com discernimento e consciência (MATOS et al., 2014).

Gonçalves et al. (2012) observaram que o conhecimento dos entrevistados se mostra satisfatório em relação à prevenção e controle do vetor, porém nos domicílios e arredores foi encontrada grande quantidade de criadouros potenciais. Para Matos et al. (2014), a problemática em relação a atitudes contrárias ao conhecimento se deve por vários fatores: 1) a falta de capacidade do indivíduos de elaborar de forma abstrata um entendimento do processo de transmissão e instalação das patologias "como um vírus invisível pode ser letal?"; 2) a falta de preceitos éticos onde prevenir a dengue é dever do outro; 3) à cultura popular que segue à jurisprudência do direito, em que as regras para serem cumpridas necessitam da imposição de punição determinada por órgãos competentes. Segundo os autores, a população não compreende a estreita ligação entre sua saúde e modo como o indivíduo atua sobre meio ambiente, e que esse modo de agir pode influenciar direta, positiva ou negativamente no bem-estar da comunidade. Cabe aos educadores, em todos os níveis, mudarem o comportamento da população, cabe à comunidade como um todo mudar seu comportamento e cabe ao indivíduo tomar atitudes conscientes com base nos conhecimentos adquiridos (MATOS et al., 2014). 


\section{CONSIDERAÇÕES FINAIS}

O combate e controle do A. aegypti é um processo complexo envolvendo vários atores. Como elos de uma corrente, esses atores atuam de forma distinta, em que suas atitudes somadas desencadeiam o desfecho de uma situação que em casos negativos leva ao surto de uma ou mais viroses transmitidas pelo vetor.

Este estudo demonstrou que os sujeitos entrevistados em sua maioria tem posse do conhecimento necessário para adquirir uma postura que leve a diminuição dos fatores facilitadores para infestação do vetor. Os ACE demonstraram ter maior conhecimento acerca do comportamento do vetor, apontando imóveis e atividades econômicas propícias para sua proliferação. Também atribuíram a gestão inadequada de resíduos sólidos como uma fragilidade dos serviços de saneamento municipal e indicaram os criadouros artificiais formados por resíduos sem adequado destino como o principal depósito do vetor. Da mesma forma, a população atribuiu o acúmulo de resíduos em residências e terrenos baldios como principal fator facilitador. Os dois sujeitos demonstraram consciência dos fatores climáticos e da sazonalidade em relação ao amento da circulação do vetor.

Pode-se concluir que as informações de modo geral têm atingido os atores estudados. Porém, acredita-se que assimilação dessa informação e posterior transformação em atitudes proativas seja falha. Fato confirmado pela população que apontou haver circulação suficiente de informações e, por outro lado, pelos ACE indicando a falta de participação da comunidade em geral nas ações de combate e controle.

Os achados deste estudo são valiosos para a Promoção da Saúde e Prevenção de Agravos, pois fornecem ainda mais subsídios aos gestores de saúde para o desenvolvimento de políticas e estratégias com intuito preventivo. Este estudo pode ser extrapolado visando aprofundamento da comunidade alvo, em que fatores culturais, políticos e sociais podem ser estudados em seus detalhes para elucidar a forma de construção do conhecimento e a transformação em ação, fornecendo ainda mais subsídios aos gestores de saúde para o desenvolvimento e implantação de estratégias de controle.

Recomenda-se ações voltadas a sensibilização e ao envolvimento da população no planejamento e na efetivação das políticas de prevenção de agravos e da promoção da saúde. 
A gestão em saúde deve fomentar o empoderamento de indivíduos e da população para que sejam atores ativos no cuidado do seu estado de saúde, bem como da coletividade.

\section{AGRADECIMENTOS}

À Universidade Comunitária de Região de Chapecó (Unochapecó), pela concessão de bolsa de estudo institucional integral conforme a Resolução 60/2017 e à Fundação de Amparo à Pesquisa e Inovação de Santa Catarina (FAPESC) pela concessão de bolsa de estudo conforme o artigo 171/CE (UNIEDU). À Empresa de Pesquisa Agropecuária e Extensão Rural de Santa Catarina (EPAGRI/CIRAM SC) pela disponibilização e autorização de uso dos dados climáticos.

\section{REFERÊNCIAS BIBLIOGRÁFICAS}

ALMEIDA, C. A. P.; SILVA, R. M. da. Análise da ocorrência dos casos de dengue e sua relação com as condições socioambientais em espaços urbanos: os casos de João Pessoa, Cabedelo e Bayeux, no estado da Paraíba - Brasil. Hygeia, Uberlândia, v. 14, n. 27, p. 56-79, mar. 2018. Disponível em: http://www.seer.ufu.br/index.php/hygeia/article/view/38370, acesso em 06 de junho de 2020.

AKERMAN, M.; MAYMONE, C. C.; GONÇALVES, C. B.; CHIORO, A.; BUSS, P. M. As novas agendas de saúde a partir de seus determinantes sociais. In: GALVÃO, L. C.; FINKELMAN, J.; HENAO, S. Determinantes ambientais e sociais da saúde. Rio de Janeiro: Editora Fiocruz, 2011. Disponível em: https://portal.fiocruz.br/livro/determinantes-ambientais-e-sociais-da-saude , acesso em 06 de junho de 2020.

ANS - Agência Nacional de Saúde Suplementar. Manual técnico de promoção da saúde e prevenção de riscos e doenças na saúde suplementar. 3. ed. rev. e atual. Rio de Janeiro: ANS, 2009.

BASTOS, J. L. D.; DUQUIA, R. P. Um dos delineamentos mais empregados em epidemiologia: estudo transversal. Scientia Medica, Porto Alegre, v. 17, n. 4, p. 229-232, out./dez. 2007.

BESSERA, E. B.; FERNANDES, C. R. M.; SOUSA, J. T.; FREITAS, E. M.; SANTOS, K. D. Efeito da qualidade da água no ciclo de vida e na atração para oviposição de Aedes aegypti (L.) (Diptera: Culicidae). Neotropical Entomology, Londrina, v. 39, n. 6, p. 10161023, 2010. Disponível em: https://www.scielo.br/pdf/ne/v39n6/v39n6a26.pdf , acesso em 06 de junho de 2020.

BRAGA, I. A.; VALLE, D. N. Aedes aegypti: inseticidas, mecanismos de ação e resistência. Epidemiologia e Serviços de Saúde, Brasília, v. 16, n. 4, p. 279-293, out./dez. 2007a. Disponível em: http://scielo.iec.gov.br/pdf/ess/v16n4/v16n4a06.pdf , acesso em 06 de junho de 2020 .

BRAGA, I. A.; VALLE, D. N. Aedes aegypti: vigilância, monitoramento da resistência e alternativas de controle no Brasil. Epidemiologia e Serviços de Saúde, Brasília, v. 16, n. 4, p. 295-302, out./dez. 2007b. Disponível em: http://scielo.iec.gov.br/pdf/ess/v16n4/v16n4a07.pdf , acesso em 06 de junho de 2020.

BUSS, P. M. Promoção à saúde e qualidade de vida. Ciência e Saúde Coletiva, Rio de Janeiro, v. 5, n. 1, p. 163-177, 2000. Disponível em: https://www.scielo.br/pdf/csc/v5n1/7087.pdf , acesso em 06 de junho de 2020. 
Percepções de agentes de combate a endemias e da população quanto aos fatores que influenciam na proliferação do mosquito Aedes aegypti, Chapecó (SC)

CABRAL, J. de A.; FREITAS, M. V. Distribuição espacial e determinantes socioeconômicos e demográficos da dengue nos municípios Brasileiros. Revista Brasileira de Estudos Regionais e Urbanos, São Paulo, v. 6, n. 1, p. 81-95, 2012. Disponível em: https://www.revistaaber.org.br/rberu/article/view/82, acesso em 06 de junho de 2020.

CAMPOS, M. de O.; NETO, J. F. R. Qualidade de vida: um instrumento para a promoção a saúde. Revista Baiana de Saúde Pública, Salvador, v. 32, n. 2, p. 232-240, maio/ago. 2008. Disponível em: http://rbsp.sesab.ba.gov.br/index.php/rbsp/article/view/1438, acesso em 06 de junho de 2020.

CESAR, F. de P. B.; LABINAS, A. M. A influência da temperatura na frequência e sazonalidade do mosquito Aedes aegypti no município de Ubatuba - SP. In: ENCONTRO LATINO AMERICANO DE INICIAÇÃO CIENTÍFICA, 11., 2007, São José dos Campos. Anais... São José dos Campos: Universidade do Vale do Paraíba, 2007. p. 3043-3046.

COSTA, F. S.; SILVA, J. J. da; SOUZA, C. M. de; MENDES, J. Dinâmica populacional de Aedes aegypti (L) em área urbana de alta incidência de dengue. Revista da Sociedade Brasileira de Medicina Tropical, Uberaba, v. 41, n. 3, p. 309-312, maio/jun. 2008. Disponível em: https://www.scielo.br/pdf/rsbmt/v41n3/a18v41n3.pdf, acesso em 06 de junho de 2020.

CZERESNIA, D.; FREITAS, C. M. (Org.). Promoção da Saúde: conceitos, reflexões, tendências. Rio de Janeiro: Editora Fiocruz, 2003.

DALMOLIN, B. B.; BACKES, D. S.; ZAMBERLAN, C.; SCHAURICH, D.; COLOMÉ, J. S.; GEHLEN, M. H. Significados do conceito de saúde na perspectiva de docentes da área da saúde. Escola Anna Nery Revista de Enfermagem, Rio de Janeiro, v. 15, n. 2 , p. 389-394, 2011. Disponível em: https://www.scielo.br/pdf/ean/v15n2/v15n2a23.pdf, acesso em 06 de junho de 2020.

FEITOSA, F. R. S.; SOBRAL, I. S.; SILVA, M. dos. F. da;JESUS, E. N. de. Estratégias de prevenção e controle da dengue em Aracaju: potencialidades e fragilidades. Caminhos de Geografia, Uberlândia, v. 17, n. 60, p. 149-168, dez. 2016. Disponível em: https://periodicos.ufsm.br/reget/article/view/18239, acesso em 06 de junho de 2020.

FEITOSA, F. R. S.; SOBRAL, M. do S. F. da; JESUS, E. N. Indicadores Socioambientais como subsídio à prevenção e controle da Dengue. Revista Eletrônica em Gestão, Educação e Tecnologia Ambiental, Santa Maria, v. 19, n. 3, p. 351-368, set./dez. 2015. Disponível em: https://periodicos.ufsm.br/reget/article/view/18239, acesso em 06 de junho de 2020.

FERREIRA, A. C.; CHIARAVALLOTI NETO, F. Infestação de área urbana por Aedes aegypti e relação com níveis socioeconômicos. Revista Saúde Pública, São Paulo, v. 41, n. 6, p. 915-922, 2007. Disponível em: https://www.scielo.br/pdf/rsp/v41n6/en_6136.pdf, acesso em 06 de junho de 2020.

GONÇALVES, R. C.; TAVARES, M. L.; FALEIRO, J. H.; RODRIGUES, A. S. DE L.; MALAFAIA, G. Dengue em Urutaí, GO: conhecimentos, percepções da população e condições sanitárias de suas residências. Arquivos Brasileiros de Ciências da Saúde, Santo André, v. 37, n. 1, p. 36-43, jan./abr. 2012. Disponível em: https://webcache.googleusercontent.com/search, acesso em 06 de junho de 2020.

HORTA, M. A. P.; FERREIRA, A. P.; OLIVEIRA, R. B. de; WERMELINGER, E. D.; KER, F. T. DE O.; FERREIRA, A. C. N.; CATITA, C. M. S. Os efeitos do crescimento urbano sobre a Dengue. Revista Brasileira de Promoção à Saúde, Fortaleza, v. 26, n. 4, p. 539547, out./dez. 2013. Disponível em: https://www.redalyc.org/pdf/408/40831096012.pdf, acesso em 06 de junho de 2020.

IBGE - Instituto Brasileiro de Geografia e Estatística. Censo Brasileiro de 2010. Rio de Janeiro: IBGE, 2013. Disponível em: https://censo2010.ibge.gov.br/resultados.html, acesso em 06 de junho de 2020.

IBGE - Instituto Brasileiro de Geografia e Estatística. Cidades. 2019. Disponível em: <http://cidades.ibge.gov.br/painel/painel.php?codmun=420420>. Acesso em: 20 de dezembro de 2016.

INPE - Instituto Nacional de Pesquisas Espaciais. Centro de Previsão de Tempo e Estudos Climáticos. 2016. Disponível em: <http://www.cptec.inpe.br/>. Acesso em: 17 de janeiro de 2017.

JARA, J. J.; HIDALGO, M. T.; HANSEN, R. S. A cidade na perspectiva dos determinantes da saúde. In: GALVÃO, L. C.; FINKELMAN, J.; HENAO, S. Determinantes ambientais e sociais da saúde. Rio de Janeiro: Editora Fiocruz, 2011. Disponível em: https://portal.fiocruz.br/livro/determinantes-ambientais-e-sociais-da-saude, acesso em: 06 de junho de 2020.

LOPES, N.; NOSAWA, C.; LINHARES, R.E.C. Características gerais e epidemiologia dos arbovírus emergentes no Brasil. Revista Pan-Amazônica de Saúde, Ananindeua, v. 5, n. 3, p. 55-64, 2014. Disponível em: http://scielo.iec.gov.br/pdf/rpas/v5n3/v5n3a07.pdf, acesso em: 06 de junho de 2020.

MACHADO, J. P.; OLIVEIRA, R. M.; SOUZA-SANTOS, R. Análise espacial da ocorrência de dengue e condições de vida na cidade de Nova Iguaçu, Estado do Rio de Janeiro, Brasil. Cadernos de Saúde Pública, Rio de Janeiro, v. 25, n. 5, p. 1025-1034, maio 2009. Disponível em: https://www.scielo.br/pdf/csp/v25n5/09.pdf, acesso em: 06 de junho de 2020. 


\section{Salvi et al.}

MARCONDES, C. B. Entomologia Médica e Veterinária. 2. ed. São Paulo: Atheneu, 2011.

MATOS, A. P. C. de; VASCONCELOS, C.; CAPRARA, A.; SOUSA, R. A. de. Do conhecimento à ação: o enfoque da Ecossaúde no contexto da dengue a partir de uma experiência de educação popular. Revista Brasileira de Pesquisa em Saúde, Vitória, v. 16, n. 4, p. 63-71, out./dez. 2014. Disponível em: https://www.scielo.br/pdf/csc/v18n5/36.pdf, acesso em: 06 de junho de 2020 .

MENDONÇA, F. de A.; SOUZA, A. V.; DUTRA, D. de A. Saúde pública, urbanização e dengue no Brasil. Sociedade \& Natureza, Uberlândia, v. 21, n. 3, p. 257-269, dez. 2009. Disponível em: https://www.scielo.br/pdf/sn/v21n3/a03v21n3.pdf, acesso em: 06 de junho de 2020 .

MICROSOFT INC. Project for Windows 2016: project planning software. [S.l.]: Microsoft Corporation, 2016. Conjunto de programas. 2016.

OLIVEIRA, R. L. Biologia e comportamento do vetor. In: VALLE, D.; PIMENTA, D. N.; CUNHA, R. V. (Org.). Dengue: teorias e práticas. Rio de Janeiro: Editora Fiocruz, 2015.

PIMENTA, D. N. A (des)construção da dengue: de tropical a negligenciada. In: VALLE, D.; PIMENTA, D. N.; CUNHA, R. V. (Org.). Dengue: teorias e práticas. Rio de Janeiro: Editora Fiocruz, 2015.

REY, J. R.; LOUBINOS, P. Ecología de Aedes aegypti y Aedes albopictus em América y transmisión enfermidades. Biomédica, Bogotá, n. 35, p. 177-185, 2015. Disponível em: https://revistabiomedica.org/index.php/biomedica/article/view/2514, acesso em: 06 de junho de 2020.

ROSSI, J. C. N.; SILVA, A. M. Diversidade de criadouros frequentados por Aedes aegypti e Aedes albopictus no estado de Santa Catarina, período de 1998 a 2007. $2008 . \quad$ Disponível em: http://www.dive.sc.gov.br/conteudos/publicacoes/tcc/Diversidade, acesso em 14 de março de 2018.

ROUQUAYROL, M. Z.; ALMEIDA FILHO, N. de. Epidemiologia \& Saúde. 5. ed. Rio de Janeiro: MEDSI, 1999. 600 p.

SEBRAE/SC - Serviço de Apoio às Micro e Pequenas Empresas de Santa Catarina. Santa Catarina em Números: Macrorregião Oeste/Sebrae/SC. Florianópolis: Sebrae/SC, 2013. 149 p. https://www.sebrae.com.br/Sebrae/Portal\%20Sebrae/Anexos/Macrorregiao\%20-\%200este.pdf, acesso em: 06 de junho de 2020.

SEGURADO, A. C.; CASSENOTE, A. J.; LUNA, E. A. L. Saúde nas metrópoles - doenças infecciosas. Estudos Avançados, São Paulo, v. 30, n. 86, 2016. Disponível em: https://www.scielo.br/pdf/ea/v30n86/0103-4014-ea-30-86-00029.pdf, acesso em: 06 de junho de 2020 .

SILVA, C. P. Aspectos epidemiológicos da infestação por Aedes aegypti (Diptera: Culicidae) nos municípios de Florianópolis, São José, Biguaçu e Palhoça e comparação com a situação do estado de Santa Catarina. $2017.76 \mathrm{f}$. Trabalho de Conclusão de Curso (Graduação em Ciências Biológicas) - Universidade Federal de Santa Catarina, Florianópolis, 2017. Disponível em: https://www.scielo.br/pdf/ea/v30n86/0103-4014-ea-30-86-00029.pdf, acesso em: 06 de junho de 2020.

SILVA, G. M.; SANTOS, A. M. dos; OLIVEIRA, C. C. da C.; VARGAS, M. M. Percepções e atitudes sobre a dengue dos usuários do sistema único de saúde no município de Aracaju, Sergipe, Brasil. Revista de Atenção Primária à Saúde, Juiz de Fora, v. 18, n. 3, p. 341-353, jul./set. 2015. Disponível em https://pesquisa.bvsalud.org/portal/resource/pt/lil-784467, acesso em: 06 de junho de 2020 .

SILVA, L. C.; SILVA, R. D. da. Percepção ambiental dos moradores da área Conjunto Cidadão e a relação com os casos de Dengue no bairro Senador Hélio Campos, Boa Vista-RR. Revista Norte Científico, Boa Vista, v. 7, n. 1, p. 140-150, dez. 2012.

TAUIL, P. L. Urbanização e Ecologia da Dengue. Cadernos de Saúde Pública, Rio de Janeiro, v. 17, Supl., p. 99-102, 2001. Disponível em https://www.scielo.br/pdf/csp/v17s0/3885.pdf, acesso em: 06 de junho de 2020.

ZARA, A. L. de S. A.; SANTOS, S. M. D.; FERNANDES-OLIVEIRA, E. S.; CARVALHO, R. G.; COELHO, G. E. Estratégias de controle de Aedes aegypti: uma revisão. Epidemiologia e Serviços de Saúde, Brasília, v. 25, n. 2, p. 391-404, abr./jun. 2016. Disponível em https://www.scielo.br/pdf/ress/v25n2/2237-9622-ress-25-02-00391.pdf, acesso em: 06 de junho de 2020.

\section{(cc) $\mathrm{Er}$}

Este trabalho está licenciado com uma Licença Creative Commons - Atribuição 4.0 Internacional. 